\title{
Immunogenetics and the design of Plasmodium falciparum vaccines for use in malaria-endemic populations
}

\author{
Magdalena Plebanski, ${ }_{1}^{1}$ Owen Proudfoot, ${ }^{1}$ Dodie Pouniotis, ${ }^{1}$ Ross L. Coppel, ${ }^{2}$ \\ Vasso Apostolopoulos, ${ }^{1}$ and Graham Flannery ${ }^{3}$ \\ ${ }^{1}$ Vaccine Development and Infectious Diseases Unit, The Austin Research Institute, Heidelberg, Victoria, Australia \\ ${ }^{2}$ Department of Microbiology and the Victorian Bioinformatics Consortium, Monash University, Victoria, Australia \\ ${ }^{3}$ Department of Genetics, LaTrobe University, Victoria, Australia
}

Address correspondence to: Magdalena Plebanski, Vaccine Development and Infectious Diseases Unit, The Austin Research Institute, A\&RMC Hospital Campus, Heidelberg, Victoria 3084, Australia. Phone: 61-3-928-70643; Fax: 61-3-928-70600; E-mail: mplebans@ari.unimelb.edu.au.

J. Clin. Invest. 110:295-301 (2002). doi:10.1172/JCI200216163.

There are about 500,000,000 cases of clinical malaria of varying severity per year. Some 2 million deaths per year result, almost all of which occur in children living in sub-Saharan Africa and are due to Plasmodium falciparum infection (1). Optimism stemming from the development of vaccines that show some protection against malaria in animals and in malaria-naive humans challenged with laboratory strains of $P$. falciparum has been dampened by their failure to provide significant, long-lasting protection to individuals living in regions where the disease is endemic. One consequence of the great number of deaths in young children is that malaria has exerted an almost unparalleled selective pressure on humans, leading to the appearance of gene polymorphisms at high frequency, including some for lethal hemoglobinopathies (2). Polymorphic forms of a number of host genes involved in immunity have been associated with protection or susceptibility to malaria. These are likely to predispose populations to unique immune response patterns to vaccines, which may enhance or interfere with their efficacy. Here, we consider some recent findings on host diversity, particularly of gene products involved in immunity. We then discuss the results from recent human vaccine trials, as well as potential strategies to optimize vaccines for use in malaria-endemic areas.

Immunity to malaria is quite complex and still not completely understood. The cellular arm of the immune system is considered more important in controlling liver-stage infections, although antibodies contribute to protection; humoral immune mechanisms may be more important in controlling the blood stages. The role of other immune system components is not as well defined, but an involvement in resistance to malaria is often inferred where a particular polymorphism is common in individuals living in malaria-endemic areas. Genes that have come under specific scrutiny include those for components of the innate and acquired immune systems: mannose-binding protein
(MBP), inducible nitric oxide synthase (iNOS), Fc receptors, cytokines and cytokine receptors, and the class I and class II MHC molecules.

\section{Innate immunity}

Innate immune components such as the opsonin MBP, whose circulating levels are influenced by a variety of polymorphic point mutations, may modify complement activation and phagocytosis during infection. Whereas one known MBP mutation shows no association with disease severity in The Gambia (3), the presence of two other variants is associated with low levels of MBP and with risk of severe malaria in Gabonese children (4). Similarly, recent data suggest a role for iNOS variants, which affect the ability of macrophages to release reactive nitrogen metabolites in response to TNF- $\alpha$ and IFN- $\gamma$, and which influence the progression to cerebral malaria (5) and to reinfection and severe infection (6). Polymorphic variants are known for many other gene products affecting innate immunity, including the complement receptor CR1, an important receptor for infected red blood cells that rosette to form aggregations of infected and uninfected cells. Rosetting parasites are more frequently found in severe malaria than are nonrosetting strains, suggesting that polymorphisms in CR1 that limit rosetting may be selected for. Polymorphisms affecting CR1 structure or density of CR1 on the red-cell surface have been described in individuals living in malaria-endemic areas of West Africa and Thailand, with low density apparently associated with increased disease severity (7).

\section{Adhesion molecules}

The presence of variants of genes encoding adhesion molecules, such as ICAM- 1 and CD36, may also affect the outcome of malarial infections. These molecules affect endothelial binding, and thus vascular occlusion, by infected erythrocytes. These molecules are also involved in the regulation of immunity; for example, 
Table 1

Summary of main definite associations with resistance or susceptibility to diverse clinical forms of malaria and polymorphisms in genes of innate and acquired resistance and immunity

\begin{tabular}{|c|c|c|c|c|}
\hline Gene product & Allelic variant & Association & Region & Reference \\
\hline \multicolumn{5}{|l|}{$\mathrm{MHC}$} \\
\hline Class I & B53 & $\begin{array}{l}\text { Protection from severe malaria } \\
\text { Protection from cerebral malaria }\end{array}$ & West Africa & 22 \\
\hline Class II & $\begin{array}{l}\mathrm{DQB} 1 * 0501 \\
\mathrm{DRB} 1 * 1302\end{array}$ & $\begin{array}{l}\text { Various clinical protective associations } \\
\text { Protection from severe malaria }\end{array}$ & $\begin{array}{l}\text { Gabon } \\
\text { Gambia }\end{array}$ & $\begin{array}{l}25 \\
22\end{array}$ \\
\hline \multicolumn{5}{|c|}{ Receptors/Ligands } \\
\hline ICAM-1 & ICAM-1(Kilifi) & Susceptibility to cerebral malaria & Kenya & 9 \\
\hline CD36 & $\begin{array}{c}\text { Deficiency allele } \\
\text { Nonsense mutation }\end{array}$ & $\begin{array}{l}\text { Susceptibility to severe malaria } \\
\text { Susceptibility to cerebral malaria } \\
\text { Protection from severe malaria }\end{array}$ & $\begin{array}{l}\text { Gambia } \\
\text { Kenya, Gambia } \\
\text { Kenya }\end{array}$ & $\begin{array}{l}10 \\
11\end{array}$ \\
\hline CR1 & LL & Susceptibility to severe malaria & Thailand & 7 \\
\hline MBP & Deficiency allele & Susceptibility to severe malaria & Gabon & 4 \\
\hline FC $\gamma \| l a$ & $\operatorname{Arg} / \operatorname{Arg} 131$ & Protection from severe malaria & Kenya & 33 \\
\hline iNOS-2 & $\begin{array}{l}-969 \text { promoter } \\
\text { NOS2-69546 }\end{array}$ & $\begin{array}{l}\text { Susceptibility to cerebral malaria } \\
\text { Protection from reinfection } \\
\text { Protection from severe malaria }\end{array}$ & $\begin{array}{l}\text { Gambia } \\
\text { Gabon } \\
\text { Gambia }\end{array}$ & $\begin{array}{l}5 \\
6\end{array}$ \\
\hline TNF- $\alpha$ & $\begin{array}{c}-308 \text { promoter } \\
-238\end{array}$ & $\begin{array}{l}\text { Susceptibility to cerebral malaria } \\
\text { Susceptibility to severe malaria } \\
\text { Susceptibility to severe malaria }\end{array}$ & $\begin{array}{c}\text { Gambia } \\
\text { Sri Lanka } \\
\text { Gambia, Kenya } \\
\text { Gambia }\end{array}$ & $\begin{array}{c}14 \\
17,61 \\
16 \\
15\end{array}$ \\
\hline
\end{tabular}

Some additional references on other issues related to these polymorphisms are listed in the text.

ICAM-1 is expressed on activated endothelial cells, dendritic cells, and lymphocytes and is preferentially upregulated on memory T cells (8). ICAM-1 binding to infected erythrocytes exhibits parasite strain specificity, and one host variant, ICAM-1(Kilifi), is associated with susceptibility to cerebral malaria in West Africa (9). CD36 is expressed on endothelial cells, platelets, macrophages, and dendritic cells and participates in phagocytosis and lipid metabolism. CD36 exons 10-12 have been shown to occur in numerous polymorphic forms in The Gambia and in Kenya, and several of these forms are associated with susceptibility to cerebral malaria (10). A subsequently described polymorphism of exon 10 confers protection against severe anemia in heterozygotes in Kenya, by reducing parasite sequestration (11). There is evidence to suggest that interaction of CD36 on dendritic cells with specific $P$. falciparum strains leads to defects in dendritic cell maturation (12). Therefore, polymorphisms in CD36 may affect the priming of immune responses during infection, as well as parasite sequestration.

Geographic heterogeneity has been observed in associations between polymorphic variants of such genes and susceptibility or resistance to malaria (Table 1). Notably, ICAM-1 variants in West Africa are not associated with disease severity (13), whereas in Kenya, susceptibility to cerebral malaria is associated with homozygosity for a common mutation in this gene (9). Excluding the potential for technical limitations of diverse studies, the finding of strong polymorphic host gene associations with protection or susceptibility to malaria in discrete geographic locations should not be discouraging but rather should be useful in providing information about how parasite diversity interacts with local human genetics. Moreover, the potential of single molecules to be under more than one type of selection pressure might contribute to the diversity of the findings. Thus, as in the examples above, cell surface molecule polymorphisms can affect both endothelial adhesion by infected red blood cells and regulation of malaria-specific immunity, as well as immunity to other major bacterial and viral pathogens. Analysis of polymorphisms within the context of distinct functional protein domains could provide new insights into the mechanisms of protective associations with malarial disease.

\section{Cytokines}

Cytokines are proteins released by cells to influence the function of other cells through specific receptor binding. Cytokines produced by lymphocytes are also known as lymphokines or interleukins (ILs). Specific immune responses to malaria parasites involve $\mathrm{CD}^{+} \mathrm{T}$ cells and $\mathrm{CD}^{+}{ }^{+} \mathrm{Th}$ cells of two types: Th1, principally activating macrophages and releasing inflammatory cytokines TNF- $\alpha$ and $-\beta$, IFN- $\gamma$, IL- $1 \beta$, and IL-12; and Th2, principally involved in B cell activation and the production of cytokines such as IL-4 and IL-10. Cytokines of one cell type usually inhibit the development of the other.

There are no clear associations described between malaria resistance and known polymorphisms in most of these cytokines. The exception is TNF- $\alpha$, whose overproduction is implicated in the pathogenesis of more severe (especially cerebral) forms of malaria (14). The main source of TNF- $\alpha$ is the macrophage, and it is 
unknown whether Th1 cells contribute, directly or indirectly (through stimulation by IFN- $\gamma$ ), to the observed high TNF- $\alpha$ levels in malaria. Polymorphic point mutations at a large number of sites in the human TNF $\alpha$ promoter region have been reported. Position -238 is associated with severe (15) or cerebral malaria or malarial anemia (16) in The Gambia, and -308 is associated with cerebral malaria in The Gambia (14) and severe anemia in Sri Lanka (17). In view of the extent of linkage disequilibrium evident in the MHC region of chromosome 6 , a clear picture of the TNF- $\alpha$ variants and their role in infections such as malaria, leishmaniasis, and leprosy may only emerge from studies of haplotype diversity. In this regard, ethnic and geographic distributions of $T N F \alpha$ haplotypes, restricted to or more common in malaria-endemic populations, are now coming to light (18), suggesting that selection has favored haplotypes involving more than one allele with malarial association.

\section{Acquired immunity}

Immunity to various stages of $P$. falciparum infection contributes to host protection (19). After an infectious mosquito bite, sporozoites either are eliminated by antibodies or proceed to infect liver cells. Cytotoxic cells and IFN- $\gamma$-secreting cells (CD8, CD4, NK cells, and $\gamma \delta \mathrm{T}$ cells) promote parasite elimination from the liver. Nitric oxide (NO) induced by IFN- $\gamma$ may be an important mediator in this process. After lysing the hepatocytes, parasites infect red blood cells, initiating the malaria blood stage, when antibodies become increasingly important because of their ability to protect red cells directly, by blocking infection, and indirectly, by promoting macrophage-mediated killing of opsonized targets. T cells can promote antibody production and can activate macrophages and neutrophils by producing IFN- $\gamma$, leading to clearance of blood-stage parasites.

\section{Antigen presentation}

The induction of malaria parasite-specific memory $\mathrm{T}$ cells from naive precursors involves interaction of the specific T cell receptor (TCR) with parasite-derived peptides complexed to MHC class I (CD8 T cells) or class II (CD4 T cells) on the surface of antigen-presenting cells (APCs). For full T cell activation, this antigen-specific signal usually requires costimulatory interactions between molecules such as CD28, which are present on $T$ cells, and others, including adhesion molecules of the B7 family, which are found on professional APCs (20). Cytokines present in the priming microenvironment additionally modulate the nature of the memory $\mathrm{T}$ cells being induced. Thus, IL-12 promotes a Th 1 secretory phenotype, whereas IL-10 favors a Tr1 (suppressor) response, and IL-4 leads to a Th2 response. CD4 T cell production of IL-2 may be further required for expansion of memory CD8 T cells after priming (20).

The MHC genes themselves are the most polymorphic in the genome, and variants of the antigen-presenting molecules of the class I and class II regions are likely to be major determinants of the success of liver-stage and blood-stage vaccines, respectively. Mouse experiments indicate a major role for IFN- $\gamma$-secreting T cells, particularly CD8 T cells, in clearance of liver-stage parasites (19). P. falciparum-specific $\mathrm{CD}^{+} \mathrm{T}$ cells are found in malaria-exposed humans, although at low precursor frequencies (21), suggesting that these responses could be boosted by vaccination. In West Africa, the human MHC class I allele B53 is associated with protection against both cerebral malaria and malarial anemia (22). Potentially consistent with these genetic association data, epitopes from liver-stage antigens are recognized by B53-specific CD8 T cells $(23,24)$.

Examination of histocompatibility leukocyte antigen (HLA) class II associations with malaria resistance or immunity has produced variable results. Reduced risk of malarial anemia is observed in The Gambia in association with DRB1*1302 (22). However, protection against severe malaria is associated with a different MHC class II allele, DRB1*0101, in Kenya (15), and in Gabon, protection against reinfection and anemia is associated with DQB $1 * 0501$ (25). The allele DQB1*0501 is associated with high IFN- $\gamma$ responses to liver-stage antigen 1 (LSA1) in Gabon (25) and with high specific antibody titer to a vaccine using the immunodominant region of $P$. falciparum circumsporozoite (CS) protein in Thailand (26). Other HLA class II alleles are associated with humoral and other responses to parasite antigens. Thus, DQB1*0301/0302 modulate the antibody response to rRAP1, whereas DQB1*0311 affects responses to rRAP2 (27). Cytokine induction by LSA1 also appears to be under complex immunogenetic control, since the $\mathrm{DQB}^{*} 0201$ and 0301 alleles have been found to favor IL- 6 and IFN- $\gamma$ induction, while DRB $1 * 06$ favors IL-10 responses (28). Cytokine responses to $P$. falciparum epitopes can vary unpredictably with HLA genotype, from Th1 (e.g., A19, B53/DQB1*0201, DQB1*0301) to Th2 $\left(\mathrm{A} 2 / \mathrm{DRB} 1{ }^{*} 06\right)$ and even the dominant production of suppressive cytokines (28). As with the above-discussed non-MHC genes, the variable findings on MHC associations with malaria severity in different geographic regions might reflect parasite variation, or selection involving other diseases acting on the host population. In addition, the failure to consistently identify protective single genes or alleles suggests that susceptibility to infection is polygenic, with one or two genes predominating, and others acting as modifiers; the latter may vary between populations. Candidates for such genes have been defined in gene-mapping studies in mice infected with various murine malaria strains, and at least three non-MHC-linked regions influencing parameters such as peak parasitemia and survival have been reported. Their importance in regulating outcome of malaria infection in humans must await the fine mapping of the genes responsible and appropriate case control studies in humans (29-31).

\section{Antibodies and the $\mathrm{Fc}$ receptor}

Antibodies that bind to the sporozoite are able to prevent hepatocyte infection (reviewed in ref. 19), and numerous studies have correlated anti-CS protein antibodies with protection in humans. Parasite antigens expressed on the surface of infected red cells or on free 
merozoites are also targeted by antibodies. The existence of large families of variable red-cell surface parasite antigens that are not cross-reactive to African serum antibodies suggests that these antibodies exert a strong immune selection pressure on the parasites (32). Specific antibody isotypes and subclasses may play diverse roles in malaria. Thus, high levels of malaria-specific cytophilic antibodies, such as IgG3, are present in malaria-exposed donors and may be protective $(33,34)$. By contrast, high IgE levels may contribute to pathology $(35,36)$. Inquiry into the involvement of Fc receptors has shown that antibodies can inhibit parasite growth by blocking red cell invasion and may enhance uptake through the $\mathrm{Fc}$ receptor and/or complement receptors on phagocytes. In a recent large-scale human case study, a functionally deleterious polymorphism at the Fc $\gamma$ receptor IIa (CD32) locus was associated with susceptibility to high-density $P$. falciparum infection, confirming that $\mathrm{Fc}$ receptor/antibody interactions are relevant in at least some clinical contexts (33).

\section{Coevolution of variable hosts and parasites}

$P$. falciparum is estimated to have separated from $P$. reichnowi soon after simian/human divergence in Africa (37). Recent analyses, considering a range of mitochondrial, intronic, and exonic DNA sequences, support $P$. falciparum spreading out of Africa 6,000 to 10,000 years ago, with the rise of agriculture $(38,39)$. In addition to environmental bottlenecks affecting the distribution of $P$. falciparum strains, large-scale human intervention, including malaria prophylaxis and treatment programs, has driven selection of specific drug resistance genes (40). The patterns of emergent resistance are reminiscent of examples of accelerated evolution in bacteria and underscore the need for an effective vaccine. They also suggest that immune prophylaxis may lead to rapid selection of vaccine-resistant strains or potentially to more virulent strains (41). Antigenic shift as observed in cycles of influenza infection has been described in $P$. falciparum. This "short-term" population evolution is probably influenced by strain-specific host immunity each malaria season. The long-term efficacy of any malaria vaccine will depend on induction of immunity not susceptible to seasonal shift. Identification of protective functionally conserved epitopes or all variants of the same protective epitope has thus far proved elusive, but the recent completion of a $P$. falciparum genome blueprint paves the way for the necessary advances.

Association of specific human HLA alleles with resistance to severe malaria indicates $T$ cells as critical in protective immunity (Table 1). Paradoxically, other human HLA alleles, such as HLA-B35 in West Africa, are associated with increased susceptibility to infection by specific parasite strains $(42,43)$. The underlying reason may be negative immune responses in humans bearing particular restricting HLA alleles to variable parasitederived $\mathrm{T}$ cell epitopes. There are two types of negative effects. First, memory T cells confronted simultaneously with two individually stimulatory variant $\mathrm{T}$ cell epitopes can receive an altered activation signal through the TCR and remain unresponsive. Costimu- lation of naive $T$ cells with such altered peptide ligands (APLs) also leads to inefficient priming, and the generation of defective memory $T$ cells, which can proliferate but cannot kill, and which fail to secrete TNF- $\alpha$ or other proinflammatory cytokines in response to parasite T cell epitopes (44). Second, T cell epitopes can actively promote the secretion of antiinflammatory cytokines (45). Costimulation of memory CD4 T cells with naturally found APLs from the CS protein of $P$. falciparum results in preferential production of IL-10, which decreases MHC class II expression on APCs, inhibits NO production, interferes with naive $\mathrm{T}$ cell stimulation, and suppresses T cell IFN- $\gamma$, TNF- $\alpha$, GM-CSF, and lymphotoxin production (46). Therefore, infection by malarial strains that induce IL-10 and express such APLs can benefit the parasite population by generally suppressing immunity.

Is turning off $T$ cells by costimulation with related peptides an Achilles' heel of the immune system that can be generally exploited by pathogens to survive? Or is this interaction between specific APL-bearing malaria parasites and an HLA allele a isolated curiosity? Thus far, APLs capable of altering T cell reactivity have been found for different CD8 and CD4 T cell epitopes in the CS protein of $P$. falciparum $(42,44,45)$. The pattern of immune reactivity to some newly identified dimorphic $T$ cell epitopes in the major $P$. falciparum blood-stage antigen merozoite surface protein 1 (MSP1) is also consistent with APLs capable of turning off immunity (47). Pathogens such as HIV and hepatitis B have now been shown to use APL antagonism as an immune-evasion strategy in individuals of the appropriate HLA type (48, 49). Evidence is rapidly accumulating that susceptibility of $T$ cells to negative APL signaling may be commonly exploited by pathogens in the interaction between specific human HLA types and strains bearing a subset of $T$ cell epitope variants.

\section{Optimizing vaccine efficacy in malaria-endemic areas}

Historically, experimental malaria vaccines have failed to protect humans living in endemic areas of Africa. A variety of new vaccines effective in protecting against malaria in murine models have been recently tested in primates and in naive humans (Table 2). Although they are generally of low potency, these vaccines can induce some malaria-specific immunity. The RTS,S vaccine, consisting of recombinant hepatitis particles containing the CS protein, induces antibodies and CD4 $\mathrm{T}$ cells and has been shown to confer $41 \%$ pre-erythrocytic protection against homologous $P$. falciparum challenge in naive volunteers (50). When administered to adults in Africa, this vaccine also induced immunity, which led to short term protection $(51,62)$.

Can vaccine design be further optimized to work effectively in malaria-endemic populations? Recent insights into the genetics of the parasite populations and their human hosts in Africa may aid vaccine design. To date, the vaccines that have been tested have usually targeted one, or at most several, proteins of the parasite. Since these proteins (such as CS and MSP1) contain 
known dominant polymorphic $\mathrm{T}$ cell epitopes, vaccination in the field is likely to target only a proportion of all parasites. As well as limiting the number of individuals protected, this approach may select a parasite population resistant to subsequent use of the vaccine. Evidence for vaccine selection of parasite populations has come from the phase IIb trial of a multicomponent vaccine in Papua New Guinea. Following inoculation with one allele of the MSP2 protein, infections and morbid episodes in the study group were preferentially associated with parasites expressing a different allele (53). Prolonged vaccination protocols requiring multiple administration doses to reach maximum immunity provide weak ongoing immunity, which may be well suited to select vaccine-resistant strains. A powerful but brief immunization schedule may help minimize this problem. In mice, single-dose vaccines able to rapidly induce long-lasting malaria blood-stage protection are being developed, so this may not be an unrealistic expectation (M. Plebanski, unpublished data).

It has been suggested that multiple variant proteins or epitopes be included in a vaccine, in order to target diverse parasite strains simultaneously. However, this not only is difficult, since parasite polymorphisms are still being identified, but may be counterproductive. Multiple variants of an epitope can compete between themselves for binding to MHC, and thus decrease immunity. In addition, as noted above, costimulation with naturally found variant peptides that are APL antagonists can actively suppress protective immune responses. Given the extensive knowledge accumulated on the nature of $\mathrm{T}$ cell repertoire/APL interactions, it is now possible to define artificial (superagonist) variants of such epitopes instead, promoting high levels of protective immunity. These variants could then be included in polyepitope vaccines.
As an alternative, selecting proteins or $\mathrm{T}$ cell epitopes conserved across $P$. falciparum strains for inclusion in polyprotein or polyepitope vaccines may be a more fruitful approach. Polyepitope-based DNA-modified vaccinia Ankara strain (MVA) prime-boost immunization went into human trial testing in 1999 after successful animal immunogenicity and protection studies against pre-erythrocytic stage infection $(54,55)$. A phase I trial of naive volunteers at the University of Oxford (Oxford, United Kingdom) has provided encouraging results (A.V.S. Hill, personal communication). On this basis, phase I human trials are being further conducted in The Gambia with malaria-exposed volunteers. In 2001, the first clinical trial of another prime-boost regime, fowlpox-MVA immunization, started at the University of Oxford (A.V.S. Hill, personal communication).

The blood-stage MSP1 antigen $19-\mathrm{kDa}$ fragment is mostly conserved and has been used to immunize malaria-naive human volunteers. It induces little antibody (56) but generates significant Th1 and Th2 CD 4 $\mathrm{T}$ cell lymphokine responses (57). Adjuvants more powerful than alum may now be tested with this promising antigen. Other largely conserved antigens from blood and liver stages, such as MSP4 and LSA3, have recently shown promise in animal models (58, 59). Because different HLA types are prevalent and associated with protection in East than in West Africa, it may be useful to focus on including combinations of epitopes and proteins recognized by such diverse HLA types in multiantigen vaccines.

Unfortunately, even powerful vaccines containing conserved targets may fail to induce the right type of immunity to be protective in Africa. Vaccines in the field do not act on a malaria-naive immune canvas but are likely to restimulate pre-existing immunity induced by previous exposure to $P$. falciparum. If prior exposure

Table 2

Summary of malaria vaccine trials performed in humans using pre-erythrocytic-stage and blood-stage proteins

\begin{tabular}{|c|c|c|c|c|}
\hline Antigen & Population & Description & Assessment & References \\
\hline \multicolumn{5}{|l|}{ Liver-stage } \\
\hline Irradiated sporozoites & Naive adults & & Protection & Reviewed in ref. 62 \\
\hline \multirow{2}{*}{$\begin{array}{l}\text { Circumsporozoite (CS) } \\
\text { protein }(\mathrm{RTS}, \mathrm{S})\end{array}$} & Naive adults & Recombinant $P$. falciparum $\mathrm{CS}$ protein & Protection & 50 \\
\hline & Gambian adults & Hepatitis B antigen subunit & Short-term protection & 52 \\
\hline CS protein (NANP) & African adults & $\begin{array}{l}\text { Synthetic sporozoite peptide } P \text {. falciparum } \\
\text { CS protein conjugate vaccine }\end{array}$ & No protection & 63 \\
\hline NYAC-Pf7 & Naive adults & $\begin{array}{l}\text { Pox-vectored, multiantigen, multistage vaccine } \\
\text { for } P \text {. falciparum (highly attenuated vaccinia virus) }\end{array}$ & T cells and antibodies & 64 \\
\hline $\operatorname{PfCSP}(\mathrm{DNA})$ & Naive adults & $\begin{array}{l}\text { VCL-2510 DNA plasmid encoding genes } \\
\text { for } P \text {. falciparum CS protein }\end{array}$ & $\begin{array}{l}\text { Cytotoxic and IFN- } \gamma- \\
\text { producing } C D 8^{+} T \text { cells }\end{array}$ & 65 \\
\hline \multicolumn{5}{|l|}{ Blood-stage } \\
\hline MSP19kd & Naive adults & $\begin{array}{l}\text { 19-kDa carboxy-terminal fragment of MSP1 } \\
\text { (blood-stage vaccine) from P. falciparum }\end{array}$ & $\begin{array}{l}\text { Antibodies } \\
\text { T cells }\end{array}$ & $\begin{array}{l}66 \\
57\end{array}$ \\
\hline \multirow[t]{2}{*}{$\begin{array}{l}\text { MSP1, MSP2, } \\
\text { ring-infected erythrocyte } \\
\text { surface antigen (RESA) }\end{array}$} & $\begin{array}{l}\text { Papa New Guinea } \\
\text { adult males }\end{array}$ & $\begin{array}{l}\text { MSP1 (190LCS.T3), Recombinant MSP2 } \\
\text { (3D7 allele) and part of RESA (C-terminal } \\
771 \text { amino acids) in montanide }\end{array}$ & $\begin{array}{l}\text { Challenged with } \\
\text { ring-stage parasites }\end{array}$ & 67 \\
\hline & & ISA 720 adjuvant & No protection & 53 \\
\hline SPf66 & African adults & $\begin{array}{l}\text { Synthetic multistage (pre-erythrocytic-stage } \\
\text { and asexual blood-stage protein of } P \text {. falciparum) } \\
\text { polypeptide vaccine conjugated to alum }\end{array}$ & No protection & $\begin{array}{c}\text { See ref. } 63 \\
\text { for meta-analysis }\end{array}$ \\
\hline
\end{tabular}


favors a Th1, Th2, or $\operatorname{Tr} 1$ (suppressor) response (45), this is likely to be conserved upon restimulation, not necessarily to the benefit of the host. In addition, the general $\operatorname{Th} 1 / \operatorname{Th} 2 / \operatorname{Tr} 1$ balance in these populations may also be affected by host infection with other pathogens. Notably, intestinal infections are particularly widespread in Africa (60) and may bias donor responsiveness toward a $\operatorname{Th} 2 / \operatorname{Tr} 1$ phenotype. This is likely to interfere with the efficient induction of Th1 immunity and thus pre-erythrocytic vaccine efficacy, and potentially erythrocytic stage protection, where this state of immunity is IFN- $\gamma$-mediated. Protocols and routes biased to induce Th1 cell immunity include the use of recombinant viral vectors, intradermal immunization, and the addition of cytokines such as IL-12 during vaccination.

\section{Future prospects}

Genomics, proteomics, and bioinformatics have now been added to scientists' arsenal for identifying additional groups of proteins for inclusion in multitargeted vaccines. The understanding of the rules of antigen processing and presentation and of $\mathrm{T}$ cell activation, as well as crystal structure analysis of antibody-antigen complexes, may help pinpoint regions of proteins able to stimulate the immune system. Structurally constrained parasite protein regions that are suitable by these criteria would offer ideal targets. Superagonist variants of $T$ cell epitopes that selectively stimulate Th1, rather than Th2 or Tr1, production may be further defined for inclusion in polyepitope vaccines to target polymorphic parasite regions $(19,45)$.

The immune status of populations upon immunization is also critical to the successful induction of protective immunity. The possibility of rational combined drug treatment (for malaria and/or other selected diseases) and vaccine administration protocols may help provide a human canvas more responsive to vaccines, as negative pathogen immunoregulatory effects are temporarily removed. Although we cannot change the genetics of human populations to make vaccines work better, understanding of the genetics of host-parasite coevolution has already proved its value by pointing out the vital role for both CD8 and CD4 T cells in protection, while genetic associations with the $\mathrm{Fc}$ receptor have clarified the role of cytophilic antibodies. Immunogenetic studies converge with laboratory studies in suggesting that a multistage malaria vaccine, capable of inducing both IFN- $\gamma$-producing cells, to target liver-stage proteins, and cytophilic antibodies, to block progression to the blood stage, may be the best hope to fight this ancient enemy.

\section{Acknowledgments}

M. Plebanski and R.L. Coppel are funded by the International Research Scholars Program of the Howard Hughes Medical Institute, and the National Health and Medical Research Council of Australia (NH-MRC). R.L. Coppel is further funded by NIH grant DK32094-10, and M. Plebanski by the Anti-Cancer Council of Victoria. V. Apostolopoulos is supported by an NH-MRC
C.J. Martin Research Fellowship 987071 and The Austin Research Institute. D. Pouniotis is funded by a Ph.D. Starfinger Scholarship. We thank our many colleagues and the volunteers who generously participated in immunological and genetic studies in malaria.

1. Snow, R.W., Craig, M., Deichmann, U., and Marsh, K. 1999. Estimating mortality, morbidity and disability due to malaria among Africa's nonpregnant population. Bull. World Health Organ. 77:624-640.

2. Kwiatkowski, D. 2000. Genetic susceptibility to malaria getting complex. Curr. Opin. Genet. Dev. 10:320-324.

3. Bellamy, R., et al. 1998. Mannose binding protein deficiency is not associated with malaria, hepatitis B carriage nor tuberculosis in Africans. QJM. 91:13-18.

4. Luty, A.J., Kun, J.F., and Kremsner, P.G. 1998. Mannose-binding lectin plasma levels and gene polymorphisms in Plasmodium falciparum malaria. J. Infect. Dis. 178:1221-1224.

5. Burgner, D., et al. 1998. Inducible nitric oxide synthase polymorphism and fatal cerebral malaria. Lancet. 352:1193-1194.

6. Kun, J.F., et al. 2001. Nitric oxide synthase 2(Lambarene) (G-954C), increased nitric oxide production, and protection against malaria. J. Infect. Dis. 184:330-336.

7. Nagayasu, E., et al. 2001. CR1 density polymorphism on erythrocytes of falciparum malaria patients in Thailand. Am. J. Trop. Med. Hyg. 64:1-5.

8. Luettig, B., Sponholz, A., Heerwagen, C., Bode, U., and Westermann, J. 2001. Recent thymic emigrants $\left(\mathrm{CD} 4^{+}\right)$continuously migrate through lymphoid organs: within the tissue they alter surface molecule expression. Scand. J. Immunol. 53:563-571.

9. Fernandez-Reyes, D., et al. 1997. A high frequency African coding polymorphism in the N-terminal domain of ICAM-1 predisposing to cerebral malaria in Kenya. Hum. Mol. Genet. 6:1357-1360.

10. Aitman, T.J., et al. 2000. Malaria susceptibility and CD36 mutation. Nature. 405:1015-1016.

11. Pain, A., et al. 2001. A non-sense mutation in $\mathrm{Cd} 36$ gene is associated with protection from severe malaria. Lancet. 357:1502-1503.

12. Urban, B.C., et al. 1999. Plasmodium falciparum-infected erythrocytes modulate the maturation of dendritic cells. Nature. 400:73-77.

13. Bellamy, R., Kwiatkowski, D., and Hill, A.V. 1998. Absence of an association between intercellular adhesion molecule 1, complement receptor 1 and interleukin 1 receptor antagonist gene polymorphisms and severe malaria in a West African population. Trans. R. Soc. Trop. Med. Hyg. 92:312-316.

14. McGuire, W., Hill, A.V., Allsopp, C.E., Greenwood, B.M., and Kwiatkowski, D. 1994. Variation in the TNF-alpha promoter region associated with susceptibility to cerebral malaria. Nature. 371:508-510.

15. Hill, A.V. 1996. Genetic susceptibility to malaria and other infectious diseases: from the MHC to the whole genome. Parasitology. 112(Suppl.):S75-S84.

16. McGuire, W., et al. 1999. Severe malarial anemia and cerebral malaria are associated with different tumor necrosis factor promoter alleles. J. Infect. Dis. 179:287-290.

17. Wattavidanage, J., et al. 1999. TNFalpha*2 marks high risk of severe disease during Plasmodium falciparum malaria and other infections in Sri Lankans. Clin. Exp. Immunol. 115:350-355.

18. Lamsis, S., et al. 2002. Alleles and haplotypes of tumor necrosis factor (TNF) alpha and beta genes in three ethnic populations of Sulawesi, Indonesia. Hum. Biol. 74:381-396.

19. Plebanski, M., and Hill, A.V. 2000. The immunology of malaria infection. Curr. Opin. Immunol. 12:437-441.

20. Jankovic, D., Sher, A., and Yap, G. 2001. Th1/Th2 effector choice in parasitic infection: decision making by committee. Curr. Opin. Immunol. 13:403-409.

21. Plebanski, M., Aidoo, M., Whittle, H.C., and Hill, A.V. 1997. Precursor frequency analysis of cytotoxic $\mathrm{T}$ lymphocytes to pre-erythrocytic antigens of Plasmodium falciparum in West Africa. J. Immunol. 158:2849-2855.

22. Hill, A.V., et al. 1991. Common west African HLA antigens are associated with protection from severe malaria. Nature. 352:595-600.

23. Aidoo, M., et al. 1995. Identification of conserved antigenic components for a cytotoxic $\mathrm{T}$ lymphocyte-inducing vaccine against malaria. Lancet. 345:1003-1007.

24. Hill, A.V., et al. 1992. Molecular analysis of the association of HLA-B53 and resistance to severe malaria. Nature. 360:434-439.

25. May, J., Lell, B., Luty, A.J., Meyer, C.G., and Kremsner, P.G. 2001. HLADQB1*0501-restricted Th1 type immune responses to Plasmodium falciparum liver stage antigen 1 protect against malaria anemia and reinfections. J. Infect. Dis. 183:168-172.

26. Stephens, H.A., et al. 1995. The presence of the HLA class II allele 
DPB $1 * 0501$ in ethnic Thais correlates with an enhanced vaccineinduced antibody response to a malaria sporozoite antigen. Eur. J. Immunol. 25:3142-3147.

27. Johnson, A., et al. 2000. Interaction of HLA and age on levels of antibody to Plasmodium falciparum rhoptry-associated proteins 1 and 2 . Infect. Immun. 68:2231-2236.

28. Migot-Nabias, F., et al. 2001. HLA alleles in relation to specific immunity to liver stage antigen-1 from Plasmodium falciparum in Gabon. Genes Immun. 2:4-10.

29. Ohno, T., et al. 2001. Chromosomal mapping of the host resistance locus to rodent malaria (Plasmodium yoelii) infection in mice. Immunogenetics. 53:736-740.

30. Fortin, A., et al. 2001. Identification of a new malaria susceptibility locus (Char4) in recombinant congenic strains of mice. Proc. Natl. Acad. Sci. USA. 98:10793-10798.

31. Foote, S.J., et al. 1997. Mouse loci for malaria-induced mortality and the control of parasitaemia. Nat. Genet. 17:380-381.

32. Newbold, C.I., et al. 1997. PfEMP1, polymorphism and pathogenesis. Ann. Trop. Med. Parasitol. 91:551-557.

33. Shi, Y.P., et al. 2001. Fcgamma receptor IIa (CD32) polymorphism is associated with protection of infants against high-density Plasmodium falciparum infection. VII. Asembo Bay Cohort Project. J. Infect. Dis. 184:107-111.

34. Wang, L., Richie, T.L., Stowers, A., Nhan, D.H., and Coppel, R.L. 2001. Naturally acquired antibody responses to Plasmodium falciparum merozoite surface protein 4 in a population living in an area of endemicity in Vietnam. Infect. Immun. 69:4390-4397.

35. Perlmann, P., et al. 2000. Contrasting functions of IgG and IgE antimalarial antibodies in uncomplicated and severe Plasmodium falciparum malaria. Am. J. Trop. Med. Hyg. 62:373-377.

36. Maeno, Y., et al. 2000. IgE deposition in brain microvessels and on parasitized erythrocytes from cerebral malaria patients. Am. J. Trop. Med. Hyg. 63:128-132.

37. Ayala, F.J., and Rich, S.M. 2000. Genetic variation and the recent worldwide expansion of Plasmodium falciparum. Gene. 261:161-170.

38. Volkman, S.K., et al. 2001. Recent origin of Plasmodium falciparum from a single progenitor. Science. 293:482-484.

39. Conway, D.J., et al. 2000. Origin of Plasmodium falciparum malaria is traced by mitochondrial DNA. Mol. Biochem. Parasitol. 111:163-171.

40. Read, A.F., and Taylor, L.H. 2001. The ecology of genetically diverse infections. Science. 292:1099-1102.

41. Gandon, S., Mackinnon, M.J., Nee, S., and Read, A.F. 2001. Imperfect vaccines and the evolution of pathogen virulence. Nature. 414:751-756.

42. Gilbert, S.C., et al. 1998. Association of malaria parasite population structure, HLA, and immunological antagonism. Science. 279:1173-1177.

43. Plebanski, M., Lee, E.A., and Hill, A.V. 1997. Immune evasion in malaria: altered peptide ligands of the circumsporozoite protein. Parasitology. 115(Suppl.):S55-S66.

44. Plebanski, M., et al. 1999. Altered peptide ligands narrow the repertoire of cellular immune responses by interfering with T-cell priming. Nat Med. 5:565-571.

45. Plebanski, M., et al. 1999. Interleukin 10-mediated immunosuppression by a variant CD4 $\mathrm{T}$ cell epitope of Plasmodium falciparum. Immunity. 10:651-660.

46. Akdis, C.A., and Blaser, K. 1999. IL-10-induced anergy in peripheral T cell and reactivation by microenvironmental cytokines: two key steps in specific immunotherapy. FASEB J. 13:603-609.

47. Lee, E.A., et al. 2001. Identification of frequently recognized dimorphic T-cell epitopes in Plasmodium falciparum merozoite surface protein-1 in West and East Africans: lack of correlation of immune recognition and allelic prevalence. Am. J. Trop. Med. Hyg. 64:194-203.
48. McMichael, A.J., and Phillips, R.E. 1997. Escape of human immunodeficiency virus from immune control. Annu. Rev. Immunol. 15:271-296.

49. Chisari, F.V., and Ferrari, C. 1995. Hepatitis B virus immunopathogenesis. Annu. Rev. Immunol. 13:29-60.

50. Kester, K.E., et al. 2001. Efficacy of recombinant circumsporozoite protein vaccine regimens against experimental Plasmodium falciparum malaria. J. Infect. Dis. 183:640-647.

51. Doherty, J.F., et al. 1999. A phase I safety and immunogenicity trial with the candidate malaria vaccine RTS,S/SBAS2 in semi-immune adults in The Gambia. Am. J. Trop. Med. Hyg. 61:865-868.

52. Bojang, K.A., et al. 2001. Efficacy of RTS,S/AS02 malaria vaccine against Plasmodium falciparum infection in semi-immune adult men in The Gambia: a randomised trial. Lancet. 358:1927-1934.

53. Genton, B., et al. 2002. A recombinant blood-stage malaria vaccine reduces Plasmodium falciparum density and exerts selective pressure on parasite populations in a phase $1-2 \mathrm{~b}$ trial in Papua New Guinea. J. Infect. Dis. 185:820-827.

54. Schneider, J., et al. 1998. Enhanced immunogenicity for $\mathrm{CD}^{+} \mathrm{T}$ cell induction and complete protective efficacy of malaria DNA vaccination by boosting with modified vaccinia virus Ankara. Nat. Med. 4:397-402.

55. Plebanski, M., et al. 1998. Protection from Plasmodium berghei infection by priming and boosting $\mathrm{T}$ cells to a single class I-restricted epitope with recombinant carriers suitable for human use. Eur. J. Immunol. 28:4345-4355

56. Keitel, W.A., et al. 1999. Phase I trial of two recombinant vaccines containing the $19 \mathrm{kd}$ carboxy terminal fragment of Plasmodium falciparum merozoite surface protein 1 (msp-1(19)) and T helper epitopes of tetanus toxoid. Vaccine. 18:531-539.

57. Lee, E.A., et al. 2002. Induction of T helper type 1 and 2 responses to 19kilodalton merozoite surface protein 1 in vaccinated healthy volunteers and adults naturally exposed to malaria. Infect. Immun. 70:1417-1421.

58. Kedzierski, L., Black, C.G., and Coppel, R.L. 2000. Immunization with recombinant Plasmodium yoelii merozoite surface protein $4 / 5$ protects mice against lethal challenge. Infect. Immun. 68:6034-6037.

59. Daubersies, P., et al. 2000. Protection against Plasmodium falciparum malaria in chimpanzees by immunization with the conserved pre-erythrocytic liver-stage antigen 3. Nat. Med. 6:1258-1263.

60. Stephenson, I., and Wiselka, M. 2000. Drug treatment of tropical parasitic infections: recent achievements and developments. Drugs. 60:985-995.

61. Knight, J.C., et al. 1999. A polymorphism that affects OCT-1 binding to the TNF promoter region is associated with severe malaria. Nat. Genet. 22:145-150.

62. Good, M.F., and Doolan, D.L. 1999. Immune effector mechanisms in malaria. Curr. Opin. Immunol. 11:412-419.

63. Graves, P., and Gelband, H. 2000. Vaccines for preventing malaria. Cochrane Database Syst. Rev. 2:CD000129.

64. Ockenhouse, C.F., et al. 1998. Phase I/IIa safety, immunogenicity, and efficacy trial of NYVAC-Pf7, a pox-vectored, multiantigen, multistage vaccine candidate for Plasmodium falciparum malaria. J. Infect. Dis. 177:1664-1673.

65. Wang, R., et al. 2001. Induction of $\mathrm{CD}^{+}{ }^{+} \mathrm{T}$ cell-dependent $\mathrm{CD}^{+}$type 1 responses in humans by a malaria DNA vaccine. Proc. Natl. Acad. Sci. USA. 98:10817-10822.

66. Keitel, W.A., et al. 1999. Phase I trial of two recombinant vaccines containing the $19 \mathrm{kd}$ carboxy terminal fragment of Plasmodium falciparum merozoite surface protein 1 (msp-1(19)) and T helper epitopes of tetanus toxoid. Vaccine. 18:531-539.

67. Lawrence, G., et al. 2000. Effect of vaccination with 3 recombinant asexual-stage malaria antigens on initial growth rates of Plasmodium falciparum in non-immune volunteers. Vaccine. 18:1925-1931. 